\title{
Enhancing MB-OFDM throughput with dual circular 32-QAM
}

Article

Published Version

Yang, R. and Sherratt, R.S. (2008) Enhancing MB-OFDM throughput with dual circular 32-QAM. IEEE Transactions on Consumer Electronics, 54 (4). pp. 1640-1646. ISSN 00983063 doi: https://doi.org/10.1109/TCE.2008.4711214 Available at https://centaur.reading.ac.uk/15457/

It is advisable to refer to the publisher's version if you intend to cite from the work. See Guidance on citing.

To link to this article DOI: http://dx.doi.org/10.1109/TCE.2008.4711214

Publisher: IEEE

All outputs in CentAUR are protected by Intellectual Property Rights law, including copyright law. Copyright and IPR is retained by the creators or other copyright holders. Terms and conditions for use of this material are defined in the End User Agreement.

\section{www.reading.ac.uk/centaur}

\section{CentAUR}

Central Archive at the University of Reading

Reading's research outputs online 


\title{
Enhancing MB-OFDM Throughput with Dual Circular 32-QAM
}

\author{
Runfeng Yang, Member, IEEE and R. Simon Sherratt, Senior Member, IEEE
}

\begin{abstract}
Quadrature Phase Shift Keying (QPSK) and Dual Carrier Modulation (DCM) are currently used as the modulation schemes for Multiband Orthogonal Frequency Division Multiplexing (MB-OFDM) in the ECMA-368 defined Ultra-Wideband (UWB) radio platform. ECMA-368 has been chosen as the physical radio platform for many systems including Wireless USB (W-USB), Bluetooth 3.0 and Wireless HDMI; hence ECMA-368 is an important issue to consumer electronics and the user's experience of these products.

To enable the transport of high-rate USB, ECMA-368 offers up to $480 \mathrm{Mb} / \mathrm{s}$ instantaneous bit rate to the Medium Access Control (MAC) layer, but depending on radio channel conditions dropped packets unfortunately result in a lower throughput. This paper presents an alternative high data rate modulation scheme that fits within the configuration of the current standard increasing system throughput by achieving $600 \mathrm{Mb} / \mathrm{s}$ (reliable to 3.1 meters) thus maintaining the high rate USB throughput even with a moderate level of dropped packets. The modulation system is termed Dual Circular 32-QAM (DC 32-QAM). The system performance for DC 32-QAM modulation is presented and compared with 16-QAM and DCM .
\end{abstract}

Index Terms - MB-OFDM, Frequency Diversity, DCM, Dual Circular 32-QAM.

\section{INTRODUCTION}

Ultra-Wideband (UWB) technology was historically employed in military radar systems. Recently UWB systems were proposed to standardize wide bandwidth wireless communication systems, particularly for Wireless Personal Area Networks (WPAN). The fundamental issue of UWB is that the transmitted signal can be spread over an extremely large bandwidth with a very low Power Spectral Density (PSD). In 2002, the USA Federal Communications Commission (FCC) agreed to allocate $7500 \mathrm{MHz}$ spectrum in the 3.1-10.6 GHz band for unlicensed use for UWB devices [1] and limited the UWB Effective Isotropic Radiated Power (EIRP) to $-41.3 \mathrm{dBm} / \mathrm{MHz}$ [2].

In 2005 the WiMedia Alliance [3] working with the European Computer Manufacturers Association (ECMA) announced the establishment of the WiMedia MB-OFDM (Multiband Orthogonal Frequency Division Multiplexing) UWB radio platform as their global UWB standard, ECMA-368. ECMA-368 was also chosen as physical layer

\footnotetext{
${ }^{1}$ This work was supported in part by The University of Reading Overseas Research Postgraduate Studentships.

Runfeng Yang is with the Signal Processing Laboratory (SPL), the University of Reading, RG6 6AY, UK (e-mail: r.yang@reading.ac.uk).

R. Simon Sherratt is with the Signal Processing Laboratory (SPL), the University of Reading, RG6 6AY, UK (e-mail: r.s.sherratt@reading.ac.uk).
}

Contributed Paper

Manuscript received October 16, 2008
(PHY) of high data rate wireless specifications for highspeed Wireless USB (W-USB) [4], Bluetooth 3.0 [5] and Wireless High-Definition Media Interface (HDMI) [6]. Recently ECMA-368 has published a second updated version [7].

Quadrature Phase Shift Keying (QPSK) and Dual Carrier Modulation (DCM) are exploited as modulation schemes for MB-OFDM in ECMA-368. QPSK constellation is used for data rates $200 \mathrm{Mb} / \mathrm{s}$ and lower while DCM is used as a multi-dimensional constellation for data rates $320 \mathrm{Mb} / \mathrm{s}$ and higher.

ECMA-368 offers up to $480 \mathrm{Mb} / \mathrm{s}$ instantaneous bit rates to enable the transport of high-rate USB. However the maximum data rate of $480 \mathrm{Mb} / \mathrm{s}$ in a practical environment can not be achieved due to poor radio channel conditions causing dropped packets, resulting in a lower throughput and the need to retransmit the dropped packets. To increase the bit rate and allow for effective $480 \mathrm{Mb} / \mathrm{s}$ performance even with moderate packet loss in a practical system, 16QAM can be employed as an alternative modulation scheme instead of DCM to increase the system throughput. However the system using 16-QAM has no successful multipath propagation link for transmitting at $960 \mathrm{Mb} / \mathrm{s}$ or only achieves 1.2 meters at $640 \mathrm{Mb} / \mathrm{s}$ comparing to the DCM $480 \mathrm{Mb} / \mathrm{s}$ mode and $320 \mathrm{Mb} / \mathrm{s}$ mode respectively (Appendix A). In this paper, a low cost and high performance modulation scheme termed Dual Circular 32QAM (DC 32-QAM) is proposed, implemented and tested, which increases the ECMA-368 system throughput to 600 $\mathrm{Mb} / \mathrm{s}$ (comparing to the DCM $480 \mathrm{Mb} / \mathrm{s}$ mode) with a successful link of 3.1 meters using existing ECMA-368 assumptions.

Chapter II presents the MB-OFDM background. Chapter III introduces DCM and 16-QAM. Chapter IV discusses the DC 32-QAM. Chapter V discusses a consequential bit interleaver for the DC 32-QAM. Chapter VI discusses the performance measurements and comparisons while chapter VII presents the conclusions.

\section{MB-OFDM IN ECMA-368}

ECMA-368 specifies a MB-OFDM system occupying 14 bands with a bandwidth of $528 \mathrm{MHz}$ for each band. The first 12 bands are grouped into 4 band groups (BG1-BG4), and the last two bands are grouped into a fifth band group (BG5), while BG6 contains bands 9, 10 and 11 allocated within the spectrum of BG3 and BG4, in agreement to usage within worldwide spectrum regulations. The advantage of the grouping is that the transmitter and receiver can process a smaller bandwidth signal while taking advantages from frequency hopping. 
The OFDM symbol is the basic quanta of MB-OFDM based UWB radio. Each OFDM symbol is constructed from an Inverse Fast Fourier Transform (IFFT) of a set of 128 complex valued carriers made from 100 data subcarriers, 12 pilot subcarriers, 6 NULL valued subcarriers and 10 guard subcarriers. The 10 guard subcarriers used for mitigating Inter Symbol Interference (ISI) are located on either edge of the OFDM symbol and have same value as the 5 outermost data subcarriers. In addition, the guard carriers can be used as another form of time and frequency diversity resulting in improving receiver performance [8]. Each OFDM symbol with duration of $242.42 \mathrm{~ns}$ is appended with a $70.08 \mathrm{~ns}$ ZeroPadded Suffix (ZPS) to aid multipath interference mitigation and settling times of the transmitter and receiver.

To operate the Physical layer (PHY) service interface to the Medium Access Control (MAC) service, a Physical Layer Convergence Protocol (PLCP) sublayer is defined to provide a method for converting a PSDU (PHY Service Data Unit) into a PPDU (PLCP Packet Data Unit) composed from three components (shown in Fig. 1): the PLCP preamble (containing the Packet/Frame Synchronization and the Channel Estimation sequence), the PLCP header, and the PSDU. To transmit a PSDU that contains the information bits, ECMA-368 has eight transmission modes by applying various levels of coding and diversity to offer $53.3,80,106.7,160$, $200,320,400$ or $480 \mathrm{Mb} / \mathrm{s}$ to the MAC layer. After bit interleaving, the coded and interleaved binary data sequence is mapped onto a QPSK or DCM complex constellation. The resulting complex numbers are loaded onto the data subcarriers of the OFDM symbol implemented using an IFFT to create real or complex baseband signal. Fig. 2 and 3 depict the encoding and decoding process for the scrambled PSDU respectively.

\begin{tabular}{|c|c|c|c|}
\hline \multicolumn{4}{|c|}{ PLCP Preamble } \\
\hline Packet/Frame Sync & CE Sequence & PLCP Header & PSDU \\
\hline
\end{tabular}

Fig. 1. PPDU structure

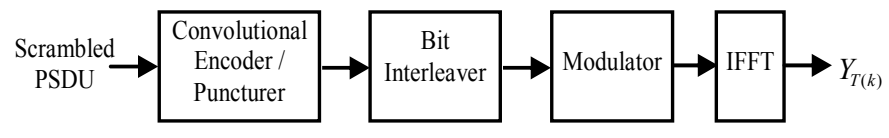

Fig. 2. Encoding process for the scrambled PSDU at Transmitter

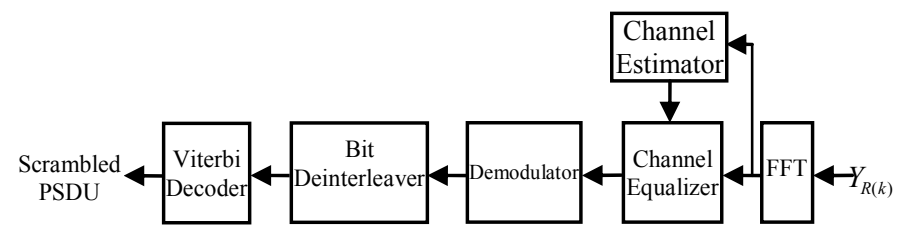

Fig. 3. Decoding process for the scrambled PSDU at Receiver

\section{DCM AND 16-QAM}

\section{A. DCM}

DCM was introduced to the MB-OFDM proposal by Batra and Balakrishnan [9] as one of the enhancement changes to the MBOA standard in order to create the current WiMedia Alliance standard. The DCM is used as a four-dimensional constellation for data rates 320,400 or $480 \mathrm{Mb} / \mathrm{s}$.

1200 interleaved and coded bits from the bit interleaver are divided into groups of 200 bits, and then these 200 bits are further grouped into 50 groups of 4 reordering bits with the four bits being mapped onto two QPSK symbols. Then the DCM mapper uses a DCM mixing matrix to execute mapping of the two QPSK symbols into two DCM symbols. The resulting DCM symbols are formed into two 16-point constellations [7] and then mapped onto two individual OFDM data subcarriers with 50 OFDM data subcarriers separation, giving at least $200 \mathrm{MHz}$ bandwidth separation. The probability that both subcarriers separated by this large bandwidth separation will experience channel deep fades is extremely small. Fig. 4 depicts the DCM mapping process.

To demap the DCM symbols at the receiver, the received and equalized symbols can be demapped by using Maximum Likely (ML) soft bit or Log-Likelihood Ratio (LLR) demapping methods with the aid of Channel State Information (CSI) as further decoding enhancement technique. The achievable system performance for $8 \%$ Packet Error Ratio (PER) [10] is approximately 3.9 meters at $480 \mathrm{Mb} / \mathrm{s}$ by using both of the aforementioned methods [11] with an implementation loss included of $2.5 \mathrm{~dB}$. However the soft bit demapping method offers lower computation complexity and extremely reduces hardware implementation cost [12].

\section{B. 16-QAM}

Rectangular Gray coded 16-QAM can be proposed as a modulation scheme to increase the system throughput. In the DCM approach, four bits from a group of 200 coded and interleaved bits are modulated into two different symbols (a complex number) which are mapped onto two different OFDM data subcarriers. If the proposed 16-QAM is employed instead of DCM, the four coded and interleaved bits modulated onto one symbol can be mapped onto one data subcarrier in an OFDM symbol. Consequently, 400 coded bits are required to map onto 100 OFDM data subcarriers. As a result, 16-QAM can increase the system throughput from $640 \mathrm{Mb} / \mathrm{s}$ to $960 \mathrm{Mb} / \mathrm{s}$ comparing to DCM $320 \mathrm{Mb} / \mathrm{s}$ to $480 \mathrm{Mb} / \mathrm{s}$ mode (Appendix A). However there is no successful link under multipath interference (Forester's Channel Model 1 [13]) transmitting at $960 \mathrm{Mb} / \mathrm{s}$ or the system has poor performance only achieving 1.2 meters at $640 \mathrm{Mb} / \mathrm{s}$ in multipath environments. 


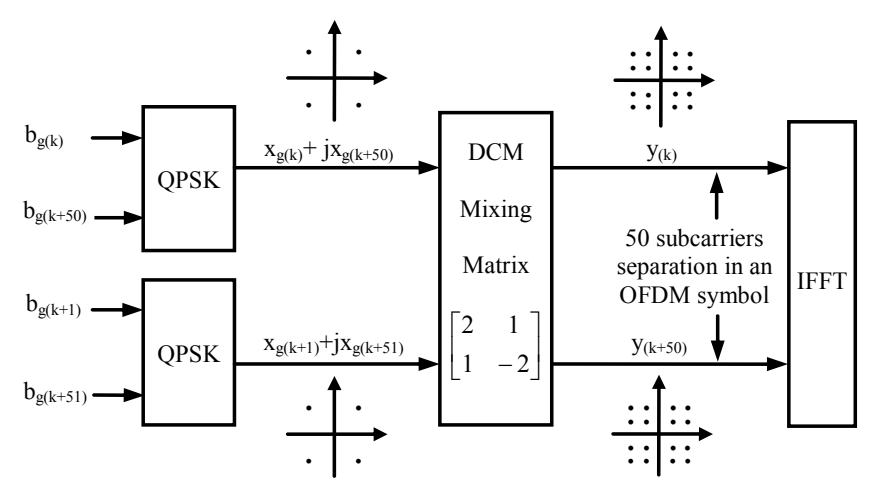

Fig. 4. DCM mapping process

\section{Dual Circular 32-QAM}

A DC 32-QAM modulator is proposed as an alternative modulation scheme that fits into the existing ECMA-368 standard structure with the objective to map more information bits onto an OFDM symbol, while at the same time providing enough Euclidean symbol distance to maintain successful transmission in multipath environments at the higher data rates. 250 interleaved and coded bits are mapped by the DC 32-QAM onto 100 data subcarriers in an OFDM symbol, which results in increasing the system throughput to $600 \mathrm{Mb} / \mathrm{s}$ comparing to the DCM $480 \mathrm{Mb} / \mathrm{s}$ mode (Appendix A).

\section{A. Frequency Diversity}

The information on a single OFDM subcarrier is unreliable if the channel has deep frequency selective fading. The information mapped onto two neighboring OFDM subcarrier will still experience channel deep fades. It is known that the DCM has experienced a good performance gain by exploiting frequency diversity [11]. Hence the DC 32-QAM will use frequency diversity with large bandwidth separation.

\section{B. Dual Circular 32-QAM constellation mapping}

After bit interleaving, 1500 coded and interleaved bits are required to divide into groups of 250 bits and then further grouped into 50 groups of 5 reordering bits. Each group of 5 bits is represented as $\left(b_{g(k)}, b_{g(k)+50}, b_{g(k)+51}, b_{g(k)+100,} b_{g(k)+101}\right)$, where $\mathrm{k} \in[0 \ldots 49]$ and

$$
g(k)=\left\{\begin{array}{cc}
2 k & k \in[0 \ldots 24] \\
2 k+50 & k \in[25 \ldots 49]
\end{array}\right.
$$

Four bits $\left(\mathrm{b}_{\mathrm{g}(\mathrm{k})+50}, \mathrm{~b}_{\mathrm{g}(\mathrm{k})+51}, \mathrm{~b}_{\mathrm{g}(\mathrm{k})+100,} \mathrm{~b}_{\mathrm{g}(\mathrm{k})+101}\right)$ are mapped across

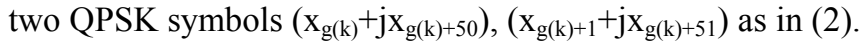

$$
\left[\begin{array}{c}
x_{g(k)}+j x_{g(k)+50} \\
x_{g(k)+1}+j x_{g(k)+51}
\end{array}\right]=\left[\begin{array}{l}
\left(2 b_{g(k)+50}-1\right)+j\left(2 b_{g(k)+100}-1\right) \\
\left(2 b_{g(k)+51}-1\right)+j\left(2 b_{g(k)+101}-1\right)
\end{array}\right]
$$

These two QPSK symbols are then mapped into two DC 32QAM symbols $\left(y_{\mathrm{T}(\mathrm{k})}, y_{\mathrm{T}(\mathrm{k}+50)}\right)$ depending on value of the first

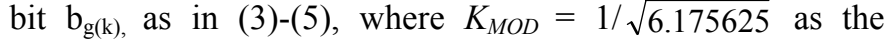

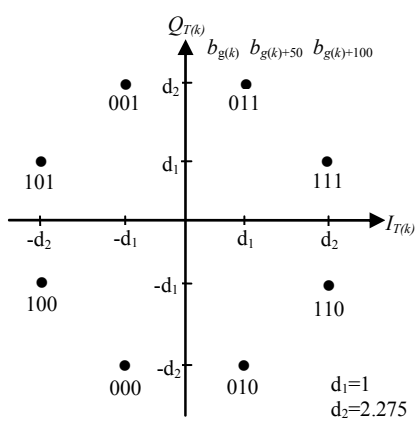

(a)

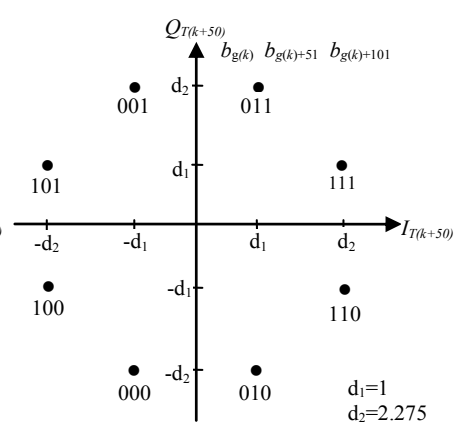

(b)
Fig. 5. Dual Circular 32-QAM constellation mapping: (a) mapping for $y_{T(\mathrm{k})}$; (b) mapping for $y_{T(\mathrm{k}+50)}$

normalization factor. The resulting symbols are formed into DC 32-QAM constellations as illustrated in Fig. 5. The constellation points are positioned in a circular loci to offer constant power for each DC 32-QAM symbol.

$$
\left[\begin{array}{c}
y_{T(k)} \\
y_{T(k+50)}
\end{array}\right]=K_{M O D}\left[\begin{array}{c}
\alpha x_{g(k)}+j \beta x_{g(k)+50} \\
\alpha x_{g(k)+1}+j \beta x_{g(k)+51}
\end{array}\right]
$$

$$
\text { where } \begin{aligned}
\alpha & =\left\{\begin{array}{cc}
1 & , b_{g(k)}=0 \\
2.275 & , b_{g(k)}=1
\end{array}\right. \\
\beta & =\left\{\begin{array}{cl}
2.275, & , b_{g(k)}=0 \\
1, & , b_{g(k)}=1
\end{array}\right.
\end{aligned}
$$

Then the two resulting DC 32-QAM symbols $\left(y_{\mathrm{T}(\mathrm{k})}, y_{\mathrm{T}(\mathrm{k}+50)}\right)$ are allocated into two individual OFDM data subcarriers with 50 subcarriers separation to achieve frequency diversity. An OFDM symbol is formed from the 128pt IFFT block requiring 100 DC 32-QAM symbols. Each OFDM subcarrier occupies a bandwidth of about $4 \mathrm{MHz}$ being the same as ECMA-368, therefore the bandwidth between the two individual OFDM data subcarriers related to the two complex numbers $\left(\mathrm{I}_{\mathrm{T}(\mathrm{k})}\right.$, $\left.\mathrm{Q}_{\mathrm{T}(\mathrm{k})}\right)$ and $\left(\mathrm{I}_{\mathrm{T}(\mathrm{k}+50)}, \mathrm{Q}_{\mathrm{T}(\mathrm{k}+50)}\right)$ is at least $200 \mathrm{MHz}$, which offers a frequency diversity gain against channel deep fading. This will also benefit for recovering the five information bits mapped across the two DC 32-QAM symbols. Fig. 6 depicts the DC 32-QAM mapping process.

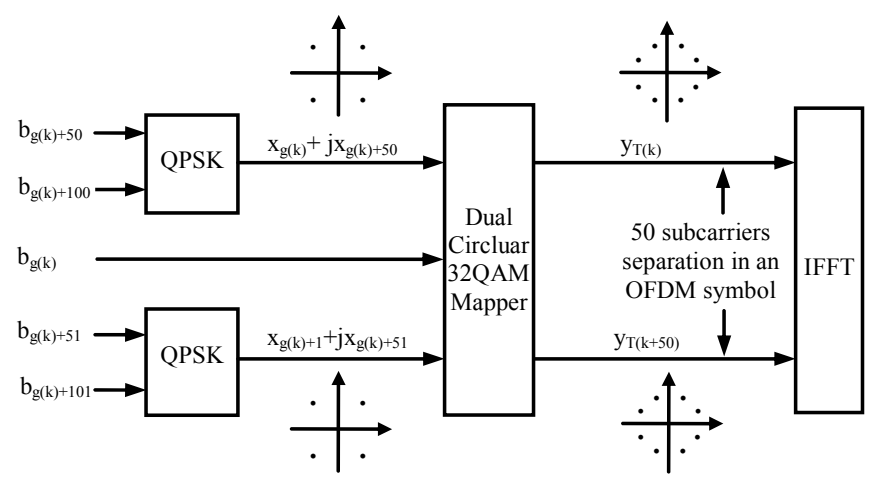

Fig. 6. Dual Circular 32-QAM mapping process 


\section{Dual Circular 32-QAM demapping}

The proposed DC 32-QAM utilizes soft bit demapping to demap two equalized complex numbers previously transmitted on different data subcarriers, as in (6), into a subgroup of 5 soft bits, and then outputs groups of 250 soft bits in sequential order.

$$
\left[\begin{array}{c}
I_{R(k)}+j Q_{R(k)} \\
I_{R(k+50)}+j Q_{R(k+50)}
\end{array}\right]=\left[\begin{array}{c}
h_{k} \\
h_{k+50}
\end{array}\right] \times \frac{1}{K_{M O D}}\left[\begin{array}{c}
\alpha x_{g(k)}+j \beta x_{g(k)+50} \\
\alpha x_{g(k)+1}+j \beta x_{g(k)+51}
\end{array}\right]+\left[\begin{array}{c}
n_{k} \\
n_{k+50}
\end{array}\right]
$$

where $\left[h_{k} h_{k+50}\right]^{T}$ are channel coefficients and $\left[\begin{array}{ll}n_{k} & n_{k+50}\end{array}\right]^{T}$ is noise. Each soft bit value of $b_{g(k)+50}, b_{g(k)+51}, b_{g(k)+100}$ and $b_{g(k)+101}$ depend on the soft bit magnitude of the I/Q completely. In addition, each soft bit can be demapped from its associated $\left(\mathrm{I}_{\mathrm{R}(\mathrm{k})}, \mathrm{Q}_{\mathrm{R}(\mathrm{k})}\right)$ and $\left(\mathrm{I}_{\mathrm{R}(\mathrm{k}+50)}, \mathrm{Q}_{\mathrm{R}(\mathrm{k}+50)}\right)$ independently. Suppose the symbols are received through the channel with no noise and multipath, then $\left[h_{k} h_{k+50}\right]^{\mathrm{T}}=\left[\begin{array}{ll}1 & 1\end{array}\right]^{\mathrm{T}}$ and $\left[\begin{array}{ll}n_{k} & n_{k+50}\end{array}\right]^{T}=$ $\left[\begin{array}{ll}0 & 0\end{array}\right]^{\mathrm{T}}$. Furthermore, the demapping performance can remain without using the factor $1 / K_{M O D}$. Hence the soft bit values for $\mathrm{b}_{\mathrm{g}(\mathrm{k})+50}, \mathrm{~b}_{\mathrm{g}(\mathrm{k})+51}, \mathrm{~b}_{\mathrm{g}(\mathrm{k})+100}$ and $\mathrm{b}_{\mathrm{g}(\mathrm{k})+101}$ are given by (7), (8), (9) and (10).

$$
\begin{aligned}
& \operatorname{Soft}\left(b_{g(k)+50}\right)=I_{R(k)} \\
& \operatorname{Soft}\left(b_{g(k)+51}\right)=I_{R(k+50)} \\
& \operatorname{Soft}\left(b_{g(k)+100}\right)=Q_{R(k)} \\
& \operatorname{Soft}\left(b_{g(k)+101}\right)=Q_{R(k+50)}
\end{aligned}
$$

The general idea of demapping $b_{g(k)}$ is that the demapped information bit is considered to be zero if the received symbol is close to the constellation point along with I axis, otherwise it is one if close to the constellation point along with $\mathrm{Q}$ axis, which is illustrated in Fig.7. Hereby, measuring the distance between the received symbol and the constellation points is required. These symbol distances are not only decided by $y_{\mathrm{R}(\mathrm{k})}$, but also decided by $y_{\mathrm{R}(\mathrm{k}+50)}$, as shown in Fig. 8 . Hence the symbol distances are calculated from Maximum Ratio Coming (MRC) distances associated with $y_{\mathrm{R}(\mathrm{k})}$ and $y_{\mathrm{R}(\mathrm{k}+50)}$, which can be simplified in (11) and (12). Furthermore, the combing distance value can be considered as using soft bit value. Therefore soft bit value of $b_{\mathrm{g}(\mathrm{k})}$ is expressed in (13).

$$
\begin{aligned}
& L 1=\sqrt{\left(\frac{\left|I_{R(k)}+I_{R(k+50)}\right|}{2}-d 1\right)^{2}+\left(\frac{\left|Q_{R(k)}+Q_{R(k+50)}\right|}{2}-d 2\right)^{2}} \\
& L 2=\sqrt{\left(\frac{\left|I_{R(k)}+I_{R(k+50)}\right|}{2}-d 2\right)^{2}+\left(\frac{\left|Q_{R(k)}+Q_{R(k+50)}\right|}{2}-d 1\right)^{2}} \\
& \operatorname{Soft}\left(b_{g(k)}\right)=L 1-L 2
\end{aligned}
$$

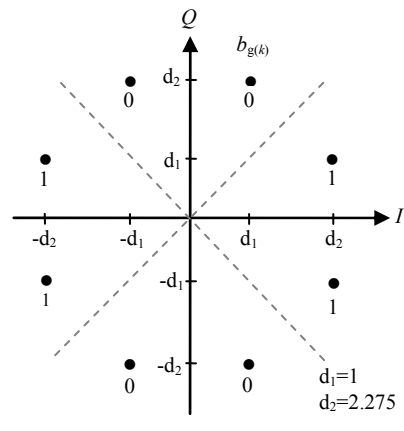

Fig. 7. Soft decision for $b_{g(k)}$

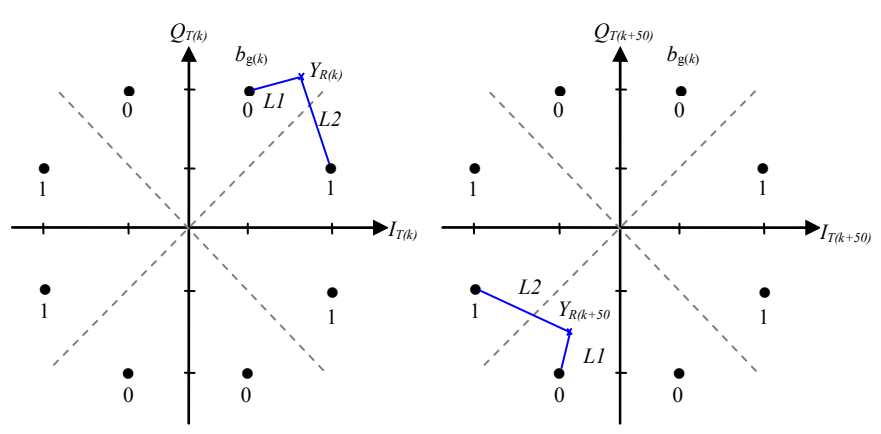

Fig. 8. Symbol distances for a possible received symbol pair $\mathrm{y}_{\mathrm{R}(\mathrm{k}) \text { and }} y_{\mathrm{R}(\mathrm{k}+50)}$

\section{Enhancement by exploiting Channel State Information}

In OFDM modulation, the OFDM subcarriers suffer from different noise power, caused by for example echoes and deep fading, etc. Each OFDM subcarrier position has a dynamic estimation for the data reliability. This dynamic estimation of the channel power in the frequency-domain is defined as the Channel State Information (CSI), which can be used to enhance the channel decoder's error correction performance [14]-[16]. Each data carrier has a potentially different CSI based on the power of the channel estimate at the corresponding frequency. The more reliable CSI is applied to the associated data subcarrier, the better decoding performance can be. The proposed CSI aided scheme coupled with the band hopping information maximizes the DCM soft demapping performance [17]. As a result, the five soft bits with incorporated CSI for the DC 32-QAM are derived as in (14)-(18).

$$
\begin{aligned}
& \operatorname{Soft}\left(b_{g(k)}\right)=(L 1-L 2) \times\left(\frac{C S I_{k}+C S I_{k+50}}{2}\right) \\
& \operatorname{Soft}\left(b_{g(k)+50}\right)=I_{R(k)} \times C S I_{k} \\
& \operatorname{Soft}\left(b_{g(k)+51}\right)=I_{R(k+50)} \times C S I_{k+50} \\
& \operatorname{Soft}\left(b_{g(k)+100}\right)=Q_{R(k)} \times C S I_{k} \\
& \operatorname{Soft}\left(b_{g(k)+101}\right)=Q_{R(k+50)} \times C S I_{k+50}
\end{aligned}
$$




\section{V.CONSEQUENTIAL BIT INTERLEAVER}

Since the DC 32-QAM can map more information bits than DCM, the structure of bit interleaver in ECMA 386 needs to be extended. The proposed bit interleaver should interleave 1500 coded bits and output to the DC 32-QAM modulator (Appendix B).

The bit interleaving operation is performed in two necessary stages and one optional stage: Symbol interleaving, which enables the PHY to exploit frequency diversity within a band group via permuting the bits across 6 consecutive OFDM symbols; Intra-symbol tone interleaving, which exploits frequency diversity across subcarriers and provides robustness against narrow-band interferes via permuting the bits across the data subcarriers within an OFDM symbol; and Intra-symbol cyclic shifts is an optional stage as it has no effect on the proposed system because the time-domain spreading mode is not enabled.

\section{SYSTEM PERFORMANCE MEASUREMENTS AND COMPARISONS}

\section{A. Simulation Configuration}

The system is simulated in a realistic multipath channel environment of 100 channel realizations in Foerster's Channel Model 1 (CM1) [13]. All simulations results are averaged over 2000 packets with 1024 octets per payload in the PSDU and 90th-percentile channel realization (the worst 10\% channels are discarded). The link success probability is defined as system can be achieved with a Packet Error Rate (PER) less than $8 \%$ [10]. We maintain strict adherence to timing and use a hopping characteristic of Time Frequency Code $(\mathrm{TFC})=1$, and incorporate $2.5 \mathrm{~dB}$ implementation loss [7] in the floating point system model, while fixed point model raises more practical loss due to quantization error [18], [19].

\section{B. Performance for Dual Carrier 32-QAM}

Fig. 9 depicts system performance (CM1, 90\%ile) adopting DC 32-QAM as the modulation scheme while exploiting frequency diversity and CSI techniques. As can be seen, DC 32-QAM offers a successful link of 3.1 meters at $600 \mathrm{Mb} / \mathrm{s}$. However, if CSI is not incorporated into DC 32-QAM demodulator, the system can achieve successful transmission in 3 meters. Frequency diversity can enhance DC 32-QAM performance by mapping the coded information onto two different OFDM subcarriers with $200 \mathrm{MHz}$ bandwidth separation. Without this large bandwidth separation, the information mapped in adjacent data subcarriers in each OFDM symbol has no robustness against channel deep fading and no signal compensation from the associated CSI. As a result the system performance drops by 0.8 meters to only achieve 2.3 meters.

\section{System performance comparisons for 16-QAM, Dual Circular 32-QAM and DCM}

To compare 16-QAM, DC 32-QAM and DCM performance, the system is configured to have the same coding rate. With changing the modulation scheme and the associated bit interleaver, the system throughput can be increased to $600 \mathrm{Mb} / \mathrm{s}$ and $960 \mathrm{Mb} / \mathrm{s}$ by DC 32-QAM and 16QAM respectively, while the DCM performs $480 \mathrm{Mb} / \mathrm{s}$.

As shown in Fig.10, there is no successful link if 16-QAM is used at $960 \mathrm{Mb} / \mathrm{s}$ (CM1, 2.5 dB implementation margin). Alternatively, lowering the data rate to $640 \mathrm{Mb} / \mathrm{s}$ by changing the coding scheme (Appendix A), the system performance is only 1.2 meters. However, by implementing the DC 32-QAM scheme presented in this paper offers 3.1 meters at $600 \mathrm{Mb} / \mathrm{s}$ while the existing system using DCM can be achieved 3.9 meters at $480 \mathrm{Mb} / \mathrm{s}$. The effective $600 \mathrm{Mb} / \mathrm{s}$ performance in practical multipath environment with moderate packet loss can offer an effective data rate at $480 \mathrm{Mb} / \mathrm{s}$.

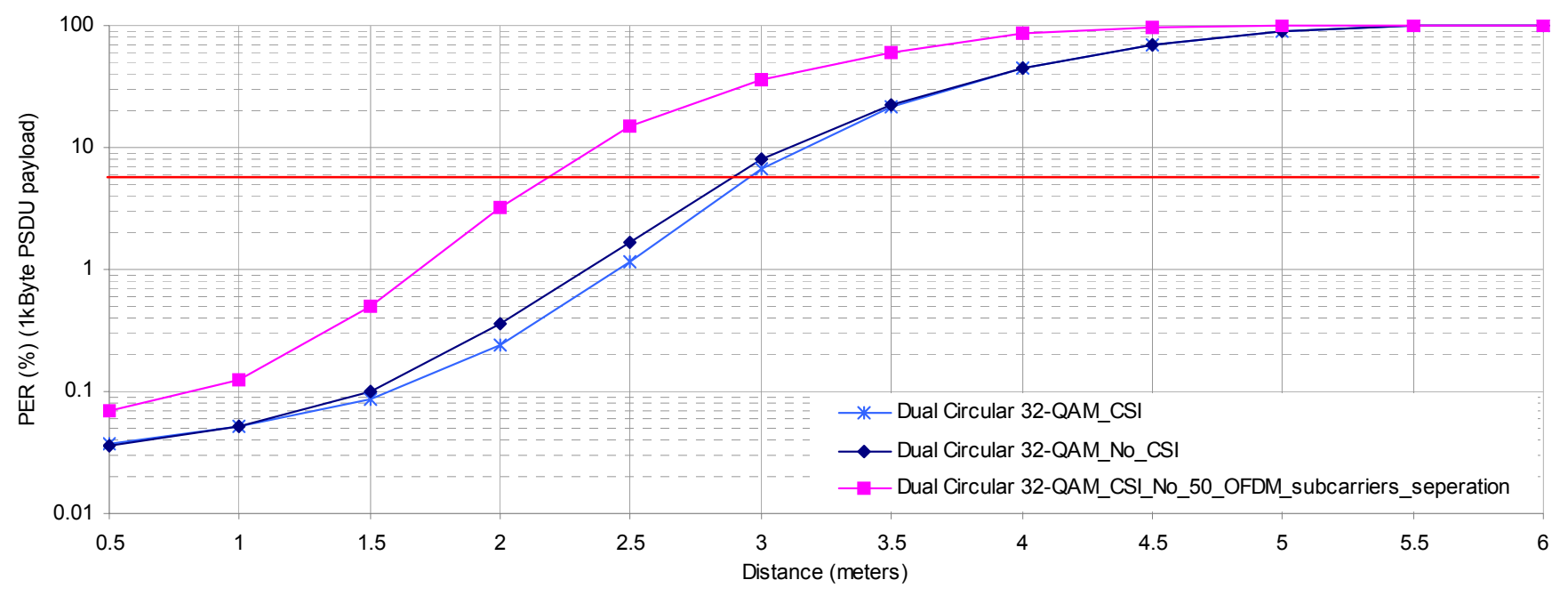

Fig. 9. System performance (in CM1) for Dual Circular 32-QAM at $600 \mathrm{Mb} / \mathrm{s}$ 


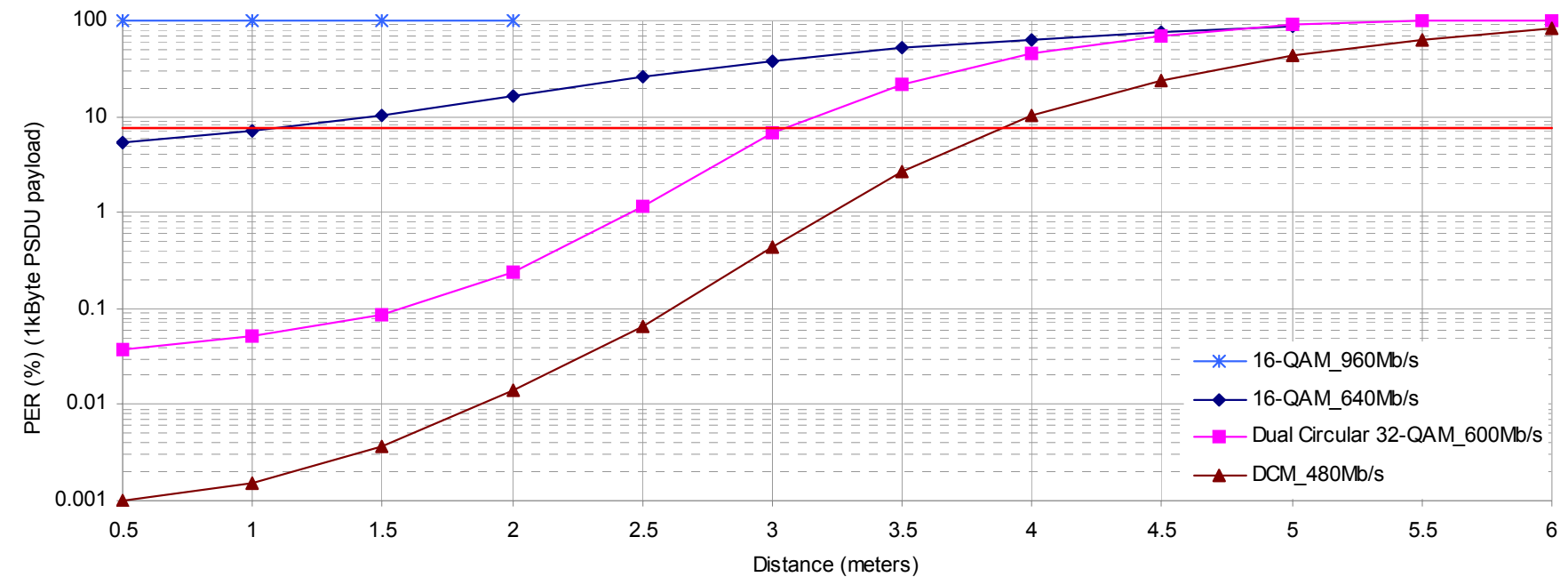

Fig. 10. System performance (in CM1) comparisons for 16-QAM, Dual Circular 32-QAM and DCM

\section{CONCLUSION}

ECMA-368 offers a robust wireless solution and low cost wireless service in Wireless Personal Area Networks (WPAN). To create a market acceptable ECMA-368 solution, the device must not only be standards conformant, but also have cost-effective, low power, high performance solutions.

This paper has proposed a cost-effective and high performance modulation scheme termed DC 32-QAM that can fit into the configuration of ECMA 368. This alternative modulation scheme can increase the system throughput to 600 $\mathrm{Mb} / \mathrm{s}$ with outputting constant modulation symbol power to achieve a successful link of 3.1 meters. Thereby an effective data rate of $480 \mathrm{Mb} / \mathrm{s}$ can be achieved with moderate packet loss, or offer a faster throughput for comparable propagation conditions.

\section{APPENDIX}

\section{A. PSDU rate-dependent Parameters}

\begin{tabular}{|c|c|c|c|c|c|}
\hline $\begin{array}{r}\text { Data Rate } \\
(\mathrm{Mb} / \mathrm{s})\end{array}$ & Modulation & $\begin{array}{c}\text { Coding } \\
\text { Rate } \\
(\mathrm{R})\end{array}$ & $\begin{array}{l}\text { Frequency } \\
\text { Domain } \\
\text { Spreading }\end{array}$ & $\begin{array}{c}\text { Time } \\
\text { Domain } \\
\text { Spreading }\end{array}$ & $\begin{array}{c}\text { Coded Bits / } \\
6 \text { OFDM } \\
\text { symbol }\left(N_{C B P 6 S}\right)\end{array}$ \\
\hline 53.3 & QPSK & $1 / 3$ & YES & YES & 300 \\
\hline 80 & QPSK & $1 / 2$ & YES & YES & 300 \\
\hline 106.7 & QPSK & $1 / 3$ & NO & YES & 600 \\
\hline 160 & QPSK & $1 / 2$ & $\mathrm{NO}$ & YES & 600 \\
\hline 200 & QPSK & $5 / 8$ & NO & YES & 600 \\
\hline 320 & DCM & $1 / 2$ & $\mathrm{NO}$ & $\mathrm{NO}$ & 1200 \\
\hline 400 & DCM & $5 / 8$ & $\mathrm{NO}$ & NO & 1200 \\
\hline 480 & DCM & $3 / 4$ & $\mathrm{NO}$ & $\mathrm{NO}$ & 1200 \\
\hline 600 & $\begin{array}{c}\text { Dual Circular } \\
\text { 32-QAM }\end{array}$ & $3 / 4$ & $\mathrm{NO}$ & NO & 1500 \\
\hline 640 & 16-QAM & $1 / 2$ & NO & NO & 2400 \\
\hline 960 & 16-QAM & $3 / 4$ & $\mathrm{NO}$ & NO & 2400 \\
\hline
\end{tabular}

B. Parameters for the Interleaver

\begin{tabular}{|c|c|c|c|c|}
\hline $\begin{array}{c}\text { Data Rate } \\
(\mathrm{Mb} / \mathrm{s})\end{array}$ & $\begin{array}{c}\text { Time Domain } \\
\text { Spreading } \\
\text { Factor }\left(N_{T D S}\right)\end{array}$ & $\begin{array}{c}\text { Coded Bits / } \\
\text { OFDM Symbol } \\
\left(N_{C B P S}\right)\end{array}$ & $\begin{array}{c}\text { Tone Interleaver } \\
\text { Block Size }\left(N_{\text {Tint }}\right)\end{array}$ & $\begin{array}{c}\text { Cyclic } \\
\text { Interleaver } \\
\text { Shift }\left(N_{c y c}\right)\end{array}$ \\
\hline 53.3 & 2 & 100 & 10 & 33 \\
\hline 80 & 2 & 100 & 10 & 33 \\
\hline 106.7 & 2 & 200 & 20 & 66 \\
\hline 160 & 2 & 200 & 20 & 66 \\
\hline 200 & 2 & 200 & 20 & 66 \\
\hline 320 & 1 & 200 & 20 & 33 \\
\hline 400 & 1 & 200 & 20 & 33 \\
\hline 480 & 1 & 200 & 20 & 33 \\
\hline 600 & 1 & 250 & 25 & - \\
\hline
\end{tabular}

\section{REFERENCES}

[1] Federal Communications Commission, "New public safety applications and broadband internet access among uses envisiged by FCC authorization of ultra-wideband technology," press released $14^{\text {th }}$ Feb 2002 ,

http://www.fcc.gov/Bureaus/Engineering_Technology/News_Releases/2 002/nret0203.html

[2] Federal Communications Commission, Revision of Part 15 of the Commissions Rules Regarding Ultra-Wideband Transmission Systems. First Report and Order, ET Docket 98-153, FCC 02-48; Adopted: February 14, 2002; Released: April 22, 2002.

http://www.fcc.gov/Bureaus/Engineering_Technology/Orders/2002/fcc0 $\underline{\text { 2048.pdf }}$

[3] WiMedia Alliance http://www.wimedia.org/en/index.asp

[4] USB-IF. Certified Wireless USB. http://www.usb.org/developers/wusb/

[5] Bluetooth SIG. http://www.bluetooth.com/Bluetooth/Press/SIG

[6] Tzero Technologies, http://www.tzerotech.com/news/recent-news/

[7] ECMA-368, "High rate ultra wideband PHY and MAC standard," December 2007,

http://www.ecma-international.org/publications/files/ECMAST/ECMA-368.pdf

[8] R. S. Sherratt and R. Yang, "A dual QPSK soft-demapper for multiband OFDM exploiting time-domain spreading and guard interval diversity," IEEE Transactions on Consumer Electronics, vol. 53, no.1, pp. 46-49, February 2007 
[9] A. Batra and J. Balakrishnan, "Improvements to the multi-band OFDM physical layer," 3rd IEEE Consumer Communications and Networking Conference, Volume 2, 8-10 Jan. 2006, pp. 701-705

[10] MBOA standard "MultiBand OFDM Physical Layer Proposal for IEEE 802.15.3a," September 2004, http://www.wimedia.org/imwp/idms/popups/pop_download.asp?Content $\underline{\mathrm{ID}=6516}$

[11] R. Yang and R. S. Sherratt, "Dual carrier modulation demapping methods and performances for Wireless USB," the 9th Annual Postgraduate Symposium (PGNET 2008), Liverpool,UK, June 2008

[12] R. Yang, R. S. Sherratt and O. Cadenas, "FPGA Based Dual Carrier Modulation Soft Mapper and Demapper for the MB-OFDM UWB Platform," EPSRC 8th Annual Postgraduate Symposium (PGNET 2007), Liverpool,UK, June 2007

[13] J. Foerster, "Channel Modeling Sub-committee Report Final," IEEE P802.15 Working Group for Wireless Personal Area Networks (WPANS), IEEE P802.15-02/490-SG3a. 7th February 2003 http://grouper.ieee.org/groups/802/15/pub/2003/Mar03/02490r1P80215 SG3a-Channel-Modeling-Subcommittee-Report-Final.zip

[14] M. R. G. Butler, S. Armour, P. N. Fletcher, A. R. Nix, and D. R. Bull, "Viterbi decoding strategies for $5 \mathrm{GHz}$ wireless LAN systems," in Proc. IEEE 54th Veh. Technol. Conf., VTC 2001 Fall, pp. $77-81$

[15] W. Lee, H. Park, and Park J., "Viterbi decoding method using channel state information in COFDM system," IEEE Transactions on Consumer Electronics, vol. 45, no. 3, pp. 533-537, August 1999.

[16] W. Li, Z. Wang, Y. Yan and M. Tomisawa, "An efficient low-cost LS equalization in COFDM based UWB systems by utilizing channel-stateinformation (CSI)," Vehicular Technology Conference, 2005. VTC2005-Fall. 2005 IEEE 62nd, Sept, 2005, Vol. 4, pp. 67-71

[17] R. Yang and R. S. Sherratt, "An Improved DCM Soft-Demapper for the MB-OFDM UWB Platform Exploiting Channel-State-Information," IEEE/IET Signal Processing for Wireless Communications, London, 6-8 June 2007

[18] R. S. Sherratt and S. Makino, "Numerical Precision Requirements on the Multiband Ultra-Wideband System for Practical Consumer Electronic Devices," IEEE Transactions on Consumer Electronics, vol 51(2), pp 368-392, May 2005

[19] R. S. Sherratt, O. Cadenas and R. Yang, "A Practical Low Cost Architecture for a MB-OFDM Equalizer (ECMA-368)," 11th Annual IEEE International Symposium of Consumer Electronics (ISCE 2007), Texas, US, June 2007

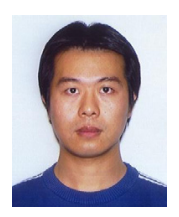

Runfeng Yang (M'06) was born in Dongguan, China. He received his B.Eng. degree in Electronic Engineering and Computer Science from the University of Reading UK in 2005. Since 2005, he started his Ph.D. in wireless USB in Electronic Engineering at the University of Reading, funded by the Oversees Research Postgraduate Studentships. He is a member of the IEEE, member of the IEEE Consumer Electronics Society (2006- ).

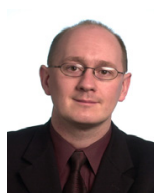

R. Simon Sherratt (M'97-SM'02) was born in Heswall, UK. He received his B.Eng. in Electronic Systems and Control Engineering from Sheffield City Polytechnic UK in 1992, M.Sc. in data telecommunications in 1994 and $\mathrm{Ph} . \mathrm{D}$. in video signal processing in 1996 both from the University of Salford. Since 1996, he has been a Lecturer in Electronic Engineering at the University of Reading where he is now a senior lecturer in consumer electronics and currently head of Electronic Engineering. His research topic is signal processing in consumer electronic devices concentrating on equalization, communications layer 1 , DSP architectures and adaptive signal processing. Eur Ing Dr. Sherratt is a senior member of the IEEE, IEEE Consumer Electronics Society Vice President (Conferences) 2008, AdCom (2003-2008), IEEE Consumer Electronics Society awards chair (2006 and 2007), member of the IEEE Transactions on Consumer Electronics publications committee (2004-), IEEE International Conference on Consumer Electronics vice-technical chair 2007, technical chair 2008 and general chair 2009, IEEE International Symposium on Consumer Electronics general chair 2004 and committee member (20022009). He received the IEEE Chester Sall $1^{\text {st }}$ place best Transactions paper award in 2004 and the best paper in the IEEE International Symposium on Consumer Electronics 2006. 